\title{
Taxonomic Implication of Integrated Chemical, Morphological, and Anatomical Attributes of Leaves of Eight Apocynaceae Taxa
}

\author{
Ahmed M. El-Taher ${ }^{1}$, Abd El-Nasser G. El Gendy ${ }^{2}{ }^{(}$, Jawaher Alkahtani $^{3}$, \\ Abdelsamed I. Elshamy ${ }^{4}(\mathbb{D})$ and Ahmed M. Abd-ElGawad ${ }^{5, *(D)}$ \\ 1 Department of Agricultural Botany, Faculty of Agriculture, Al-Azhar University, Cairo 11751, Egypt; \\ El.Taher69@yahoo.com \\ 2 Medicinal and Aromatic Plants Research Department, National Research Center, Dokki, Giza 12622, Egypt; \\ aggundy_5@yahoo.com \\ 3 Department of Botany and Microbiology, College of Science, King Saud University, \\ Riyadh 11451, Saudi Arabia; jsalqahtani@ksu.edu.sa \\ 4 Department of Natural Compounds Chemistry, National Research Center, Dokki, Giza 12622, Egypt; \\ elshamynrc@yahoo.com \\ 5 Plant Production Department (Plant Ecology), College of Food and Agriculture Sciences, \\ King Saud University, P.O. Box 2460, Riyadh 11451, Saudi Arabia \\ * Correspondence: aibrahim2@ksu.edu.sa; Tel.: +96-6562680864
}

Received: 10 August 2020; Accepted: 30 August 2020; Published: 31 August 2020

check for updates

\begin{abstract}
Up to now, the taxonomic conflict of the Apocynaceae family has attracted the attention of scientists and researchers worldwide. Recently, this family was divided into five subfamilies. The present study aims to investigate the implication of interlacing macro-, micro-morphological, anatomical, and chemical characteristics of the leaves of eight Apocynaceae plants (Adenium obesum, Dipladenia boliviensis, Carissa carandas, Nerium oleander, Asclepias curassavica, Calotropis procera, Acokanthera oblongifolia, and Thevetia neriifolia), and to provide valuable taxonomic differentiation of these species. The macro-morphological investigation includes shape, apex, base, and venation of leaves, while the micro-morphological study includes leaf epidermal cells, stomata, and trichomes. The anatomical features of the leaf blade were studied by scanning electron microscope (SEM). Additionally, the chemical composition of the silylated methanolic extract was analyzed by Gas chromatography-mass spectroscopy (GC-MS). Sixty-three compounds were characterized from the silylated extracts of the eight plants, where quinic acid, sucrose, $D$-pinitol, and $D$-(-)-fructopyranose were determined as major compounds. The Principal Component Analysis (PCA) based on the chemical composition revealed a significant chemical correlation among all species with the presence of sugars and amino acids, as well as phenolic acids and iridoid glycosides. The cluster analysis, based on all merged characters, showed that the eight species can be categorized into three clusters. The first cluster comprises A. obesum, A. curassavica, and T. neriifolia, while the second cluster contains D. boliviensis, N. oleander, A. oblongifolia, and C. carandas, and the third cluster consists of C. procera alone. This cluster revealed some similarities to the recent classification of Apocynaceae, while it showed inconsistency regarding A. obesum, C. procera, and N. oleander. Due to the obtained inconsistent data and observed variation among the studied species, further study is recommended for more characterization of these species, based on additional parameters, including molecular characteristics, particularly A. obesum, C. procera, and N. oleander.
\end{abstract}

Keywords: dogbane family; biosystematics; micro-morphology; scanning electron microscope; GC-MS; cluster analysis 


\section{Introduction}

Formerly, the Asclepiadaceae family was separated from Apocynaceae [1]. However, other authors showed that, by way of using more extensive characters, this family should be merged [2-5]. In addition, molecular studies support that Asclepiadaceae is a subclade of Apocynaceae [6,7]. Recently, Endress et al. [3] reported an updated classification of Apocynaceae, whereby Apocynaceae contains 336 genera, represented by $>4600$ species belonging to five subfamilies (Apocynoideae, Asclepiadoideae, Rauvolfioideae, Periplocoideae, and Secamonoideae). Apocynaceae is commonly known as a dogbane family, where some members of this family were characterized by a poisonous milky latex. It includes herbs, shrubs, trees, and vines.

In the flora of Egypt, the two families, Apocynaceae and Asclepiadaceae, are separated from each other. Apocynaceae is represented by two very rare wild genera and 17 cultivated genera, including 21 species; while Asclepiadaceae is represented by 12 wild genera including 18 species and six cultivated genera including six species [8,9]. The circumscription of this close set of relationships for these families has been expressed differently by taxonomists. The last classification of Apocynaceae by Endress and Bruyns [2] showed that Apocynaceae s.l. included five important subfamilies, namely: Apocynoideae, Periplocoideae, Asclepiadoideae, Secamonoideae, and Rauvolfioideae [2].

According to the literature, the plants of this family are characterized by simple leaves, with an opposite, verticillate, or alternate arrangement, and the margin is entire, undulate, or revolute [10-13]. Leaf shape could be ovate, elliptic, lanceolate, linear, obovate, elliptic-ovate, linear-lanceolate, or cordate, and rarely leafless. Leaf apex could be acuminate, obtuse, rounded, mucronate, or acute. Leaf base could be rounded, cordate, attenuate, or acute [8-10]. From an anatomical point of view, the epidermal anticlinal cell walls were thick on both leaf surfaces of Nerium indicum, Carissa carandas, and C. spinarum [14,15]. The shape of the epidermal cells regarding the border or walls is tetra, penta, or hexagonal, as in C. carandas [16], while in Caralluma sinaica it was formed by polygonal elongated papillose cells with a straight anticlinal wall [17]. The stomata in Apocynaceae plants were reported as anomocytic in Geissospermum argenteum [18] and Asclepias sp. [11], anisocytic in Catharmthus roseus, and paracytic in Carissa congesta, C. spinururn [19], and Mandevilla coccinea [20].

Al-Massarani [17] described the anatomical structure of $C$. sinaica leaves as nearly rectangular with four to six ridges and showed a stem-like structure. The epidermis was formed of polygonal axially-elongated papillose cells, with a straight anticlinal wall covered with thick striated cuticle and anomocytic stoma. Gabr et al. [12] examined the anatomical structure of the leaf of 14 species of Apocynaceae and Asclepiadaceae belonging to 14 genera, where they reported that the cuticle was thick (Acokanthera spectabilis and Carissa spinarum) or very thick (Leptadenia pyrotechnica and Thevetia peruviana), the stone cell and druses were present in some species, such as A. spectabilis and Asclepias curassavica, or absent in others. The mesophyll was isobilateral in Nerium oleander, Leptadenia arborea, Calotropis procera, and Solenostemma argel, while it was dorsiventral in others such as A. spectabilis, C. spinarum, and Cryptostegia grandiflora.

Some of the Apocynaceae species are outcrossing species, while others are predominantly selfing. In general, Apocynaceae outcrossing species are known to have high genetic diversity [21-25]. Many Apocynaceae outcrossing species have inbreeding coefficients close to zero, which indicates an outcrossing predominance. This highly xenogamous characteristic may play a crucial role in the genetic diversity of the population [26]. Many Apocynaceae members have been used in traditional medicine worldwide, they are used in the treatment of various diseases, and they have been reported to possess antimicrobial, antioxidant, anti-inflammatory, and cytotoxic activities $[17,27,28]$. Apocynaceae plants are described as rich with several secondary metabolites including flavonoids, alkaloids, sugars, terpenoids, steroids, phenols, hydrocarbons, lactones, and lignans [29]. Briefly, numerous metabolites, including flavonoids triterpenes, pregnanes, cardenolides, cardiac glycosides, and carbohydrates, were described for Adenium obesum [30]. Cardenolides, triterpenoids, and carbohydrates were identified in N. oleander [31]. A. curassavica extract was reported to have seco-triterpenoids, pregnanes, glycosides, cardenolides, and flavonoids [32,33]. Cardiac glycoside, triterpenoids, pregnanes, and their 
glycosides, phenolics, and flavonoids were isolated from C. procera [34]. Additionally, cardiac glycosides, triterpenoids, flavonoids, saponins, tannins, steroids, and sesquiterpenes were characterized from different extracts of $C$. carandas [28]. Arrays of metabolites comprising triterpenes, cardiac glycosides, cardenolide, iridoid-glucosides, and sterols were reported from Thevetia neriifolia [20]. Biologically, these plants exhibited several biological activities such as antibacterial, anticancer, anti-inflammatory, cardioprotective, analgesic, gastroprotective, antidiabetic, and hepatoprotective activity [29].

Although many botanical scientists choose the Apocynaceous plants as materials for their taxonomic researches due to its taxonomic confliction, this family still needs further studies based on more criteria to help in the clarification of its taxonomic problem. Our hypothesis suggests that the interlacing of morphological, anatomical, and chemical characters of the leaves of some Apocynaceae plants provide valuable taxonomic differentiation of these species and contribute to the separation or annexation of these species into subfamilies. Thereby, the current study aims to assess the relationships or similarities among eight Apocynaceae species, via the investigation of various morphological, anatomical, and chemical characters of the leaves. These plants were classified under three subfamilies according to Endress et al. [3]. (1) Apocynoideae subfamily (Adenium obesum (Forssk.) Roem. and Schult., Dipladenia boliviensis J.J.Veitch, and Nerium oleander L.), (2) Asclepiadoideae subfamily (Asclepias curassavica L. and Calotropis procera (Aiton) W.T. Aiton), and (3) Rauvolfioideae subfamily (Acokanthera oblongifolia (Hochst.) Benth. and Hook.f. ex B.D. Jacks., Carissa carandas L., and Thevetia neriifolia Juss. ex A.DC.).

\section{Materials and Methods}

\subsection{Plant Materials Collection, Preparation, and Identification}

Eight plants belonging to three subfamilies of the Apocynaceae family were investigated in the present study. We selected some Apocynaceae plants found under Egyptian conditions, where a little number of species were growing in Egypt; among them were only two wild species (Carissa spinarum $\mathrm{L}$. and Rhazya stricta Decne.) and the others were cultivated species such as Adenium, Dipladenia, Carissa, Nerium, and Asclepias. Fresh samples of these plants were collected from three locations. A. obesum, D. boliviensis, C. procera, A. oblongifolia, and T. neriifolia were collected from El-Orman Garden, Giza $\left(30^{\circ} 1^{\prime} 44.87^{\prime \prime} \mathrm{N}, 31^{\circ} 12^{\prime} 46.86^{\prime \prime}\right.$ E). N oleander and C. carandas were collected from El-Kanater El-Khiria, Kaluobia $\left(30^{\circ} 11^{\prime} 19.99^{\prime \prime} \mathrm{N}, 31^{\circ} 8^{\prime} 12.31^{\prime \prime}\right.$ E). Whereas, A. curassavica was collected from Nasr City, Cairo ( $30^{\circ} 3^{\prime} 17.72^{\prime \prime} \mathrm{N}, 31^{\circ} 19^{\prime} 42.40^{\prime \prime}$ E). The plant specimens were identified according to Tackholm [9] and Boulos [8]. For each species, ten fresh leaves were collected from three individuals, and all morphological parameters were investigated. For anatomical analysis, fresh and young plant materials were fixed in formalin-acetic acid-alcohol (FAA) fixative (10:5:85, v/v). While for chemical analysis, the fresh plant leaves, that were used in the morphological investigations, were dried in shaded condition, at room temperature $\left(25 \pm 3^{\circ} \mathrm{C}\right)$, till complete dryness, then ground into a fine powder and stored in a paper bag till further analysis.

\subsection{Leaf Morphology}

The macro-morphological attributes of the leaves including shape, apex, base, and venation were investigated for ten selected leaves of each species. Moreover, the micro-morphological investigation of leaf epidermal cells, stomata, and trichomes was investigated by a light microscope, regarding one selected healthy leaf. In brief, the leaf peels were prepared from the base, apex, middle lamina, and margin locations of the lower surface of mature foliage leaves. They were cleared in warm lactic acid and examined microscopically using a light microscope (Leica Application Suite, LASEZ, version 3.0.0, Leica microsystem Limited, Heerbrugg, Switzerland) to study the shapes of the epidermal cell, epidermal cell walls, as well as the type of mature stomata, and type of trichomes. Several photomicrographs were capture with a digital camera (DCM 510, 5 M pixels, CMOS chip) that 
is coupled with a light microscope. The slides were examined at the Regional Centre of Mycology and Biotechnology (RCMB), Al-Azhar University, Egypt.

\subsection{Scanning Electron Microscope (SEM)}

Fresh leaves were cut into segments with a length of 4-6 mm and fixed in glutaraldehyde (6\%, $\mathrm{pH} 7.3)$ for $12 \mathrm{~h}$ [35]. The samples were rinsed with sodium cacodylate buffer ( $0.05 \mathrm{M}, \mathrm{pH} 7.5)$, followed with distilled water, and dehydrated gradually with ethyl alcohol $(10 \%-100 \%$ for $20 \mathrm{~min}$ per each concentration). The samples were dried using a Hitachi HCP-2 critical point dryer and mounted on aluminum stubs with double-sided carbon-coated sputter coating with gold-palladium (Elko IB-3 Ion Coater). The samples were examined using JEOL (JSM-6390LV) SEM, Model JEOL-JSM-5500LV. The energy-dispersive $\mathrm{X}$-ray spectroscopy (EDX) involved both a fixing and a dehydration procedure, as in SEM. NORAN System SIX software (version 1.8) was used for imaging in the National Research Centre, Giza, Egypt.

\subsection{Leaf Blade Anatomy}

A piece of the leaf $\left(1 \mathrm{~cm}^{2}\right)$ from the middle part of each plant was taken and dehydrated in a series of ethanol (from $50 \%$ to $100 \%$ ). The specimens were then embedded in paraffin wax (m.p. $58-61{ }^{\circ} \mathrm{C}$ ) by xylol as a solvent, sectioned by at $15 \mu \mathrm{m}$ on a Jung PM 2045 rotary microtome, and mounted on glass slides using egg albumen as an adhesive agent. The wax was dissolved in xylol, and the slides were stained by light green and safranin. Permanent slides were prepared using Canada balsam as a mounting agent [36]. The photomicrographs were captured by a digital camera as described previously.

\subsection{Chemical Analysis of the Plant Materials}

Analysis of the silylated fractions of the prepared plant materials was carried out via gas chromatography/mass spectrometry (GC-MS). In Brief, the plant samples (10 mg) were extracted with methanol $(5 \mathrm{~mL})$ with frequent shaking and sonication for $30 \mathrm{~min}$, then the debris was removed via centrifugation at $12,000 \mathrm{rpm}$ for $10 \mathrm{~min}$. The methanol extract $(100 \mu \mathrm{L})$ was completely dried under a nitrogen gas stream. $\mathrm{N}$-methyl- $\mathrm{N}$-(trimethylsilyl)-trifluoroacetamide (MSTFA), diluted with anhydrous pyridine (1:1), was added to the completely dried methanol extract and incubated at $60^{\circ} \mathrm{C}$ for $45 \mathrm{~min}$, prior to the GC-MS analysis.

The GC-MS was performed as described before by Farag et al. [37,38]. Chemical components of the silylated methanolic extracts were identified based upon AMDIS software (www.amdis.net), retention indices (RIs), and the relation to $n$-alkanes $\left(\mathrm{C}_{6}-\mathrm{C}_{20}\right)$, as well as the mass spectrum proper to the spectral library collections of Wiley and NSIT database. Based upon the MET-IDEA software, peaks abundance data for multivariate data analysis were exported [38].

\subsection{Statistical Analysis}

The data of macro-, micro-morphology, and anatomy were prepared in a dataset of 80 parameters. In this dataset, if the character was present, we gave it the number 1, while if it was absent we gave it zero. Similarly, a data set of all 63 determined chemical compounds was prepared. To determine the relationships among the eight studied species, each dataset and merged datasets (morphological, anatomical, and chemical parameters) were subjected to hierarchical cluster analysis, following Ward's method to the Euclidean distances using the PRIMER software program, version 6.

In order to provide a synthetic representation of the determined chemical composition and their correlations to the plant species, we followed the approach of Legendre and Legendre [39]. A dataset of the concentrations (\%) of the 63 identified chemical compounds was subjected to principal component analysis (PCA), with plants as a principal component using XLSTAT software program ver. 2018 (Addinsoft, New York, NY, USA). 


\section{Results and Discussion}

\subsection{Macro-Morphological Attributes}

The leaf shape was varied among the studied plants, which is spathulate in $A$. obesum, ovate in $D$. boliviensis and C. carandas, oblong-lanceolate in N. oleander, lanceolate in A. curassavica, obovate in C. procera, elliptic in A. oblongifolia, and, finally, linear in T. neriifolia (Figure S1, Table S1). On the other hand, the leaf base is attenuate in A. obesum, N. oleander, A. curassavica, A. oblongifolia, and T. neriifolia, whereas it is rounded in D. boliviensis, C. procera, and C. carandas (Figure S1 and Table S1). The leaf apex is acute as in N. oleander, T. neriifolia, and A. curassavica, acuminate in D. boliviensis, C. procera, and C. carandas, obtuse in A. oblongifolia, and mucronate in A. obesum. The reticulate venation is common in all the studied species leaves except for $N$. oleander, which is a parallel venation. The midvein is distinct in all studied species, and the lateral veins are distinct in all species, except for C. carandas (Figure S1).

\subsection{Micro-Morphological Investigation}

\subsubsection{Epidermal Cells}

The light microscope examination of the lower epidermis of the studied species leaves showed variations among the four studied species in cell shape and cell wall (Figure 1, Table S1). The epidermal cells have thin and straight walls with polygonal, hexagonal, and pentagonal shapes in A. curassavica (Figure 1A), while they are characterized by thick walls with oblong and square shapes in $C$. carandas (Figure 1B). On the other hand, the shape of the epidermal cells of the other studied species are irregular in D. boliviensis (Figure 1C), and the ornamented epidermal cell walls are investigated in C. procera (Figure 1D).

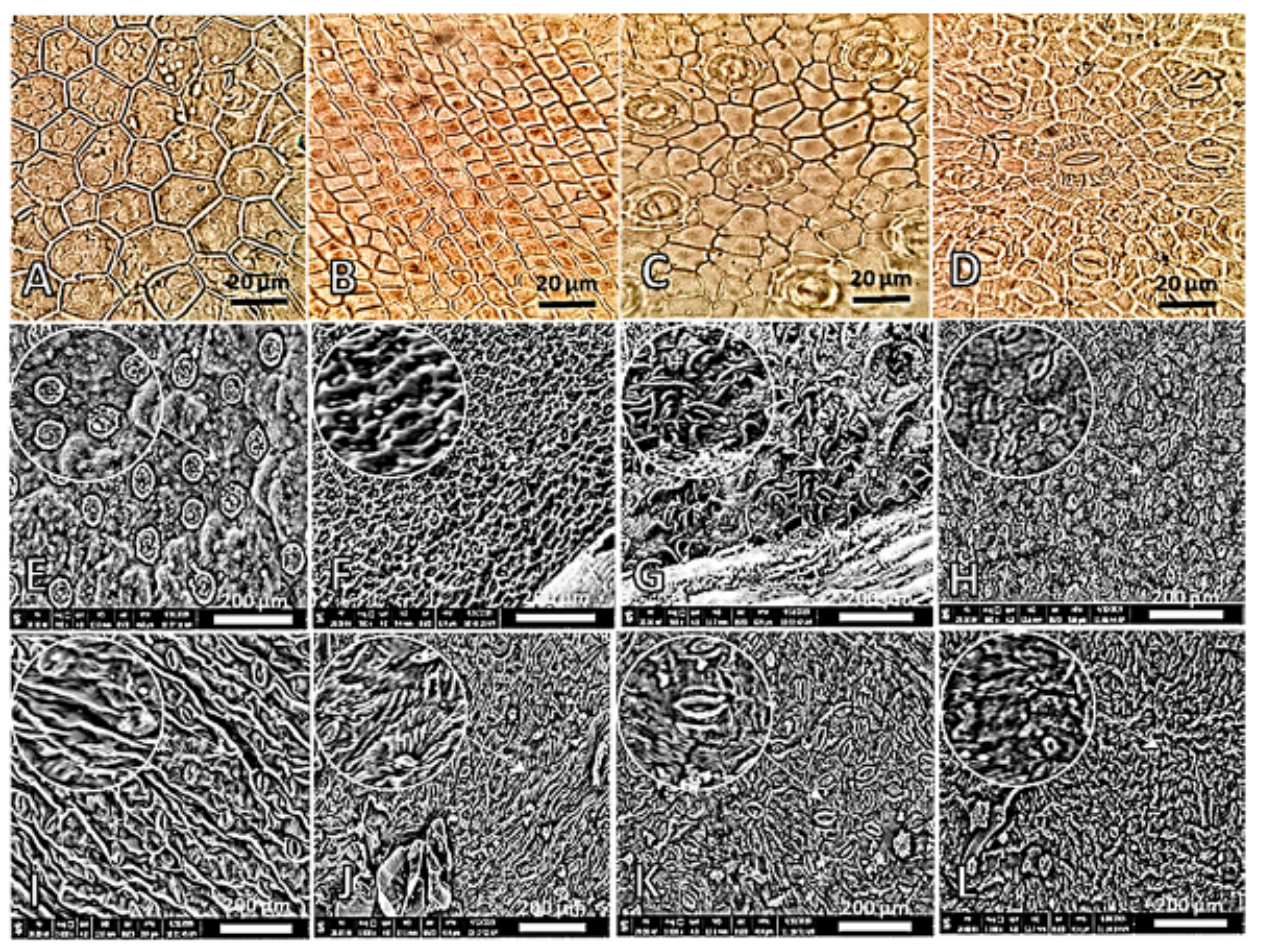

Figure 1. Different shapes of the epidermal cells of various studied Apocynaceae leaves investigated by light microscope (A-D, 140×) and scanning electron microscope (SEM) (E-L). (A,H): A. curassavica, $(\mathbf{B}, \mathbf{K})$ : C. carandas, $(\mathbf{C}, \mathbf{F})$ : D. boliviensis, $(\mathbf{D}, \mathbf{I})$ : C. procera, $(\mathbf{E})$ : A. obesum, $(\mathbf{G})$ : N. oleander, $(\mathbf{J})$ : A. oblongifolia, and (L): T. neriifolia. 
The examination of the epidermal cells with a scanning electron microscope (SEM) revealed distinct variations in the cuticle and cell wall of the epidermal cells among the studied Apocynaceous plants (Figure 1). The cuticle layer and present ornamented cell walls on the lower surface were (1) thin and warty with reticulated ornamentation in A. obesum (Figure 1E), (2) very thick and warty with reticulated and undulated ornamentation in D. boliviensis (Figure 1F), (3) thick and warty with tuberculated ornamentation in N. oleander (Figure 1G), (4) smooth and thin in A.curassavica (Figure 1H), (5) thick and straight with favulariate ornamentation in C. procera (Figure 1I), (6) thick and straight A. oblongifolia and C. carandas (Figure 1J), and (7) thick and warty with verrucose ornamentation in T. neriifolia (Figure 1L). The epidermal features of the leaves are very essential for the taxonomic conflicts $[40,41]$.

\subsubsection{Stomata}

The stomata examination by light microscope showed substantial variation among the studied species (Figure 2, Table S1). In detail, the tricytic stomata are shown in A. obesum (Figure 2A), while paracytic stomata are investigated in T. neriffolia (Figure 2B). The amphihemiparacytic and pentacytic stomata are noticed only in C. procera and D. boliviensis (Figure 2C,D, respectively).

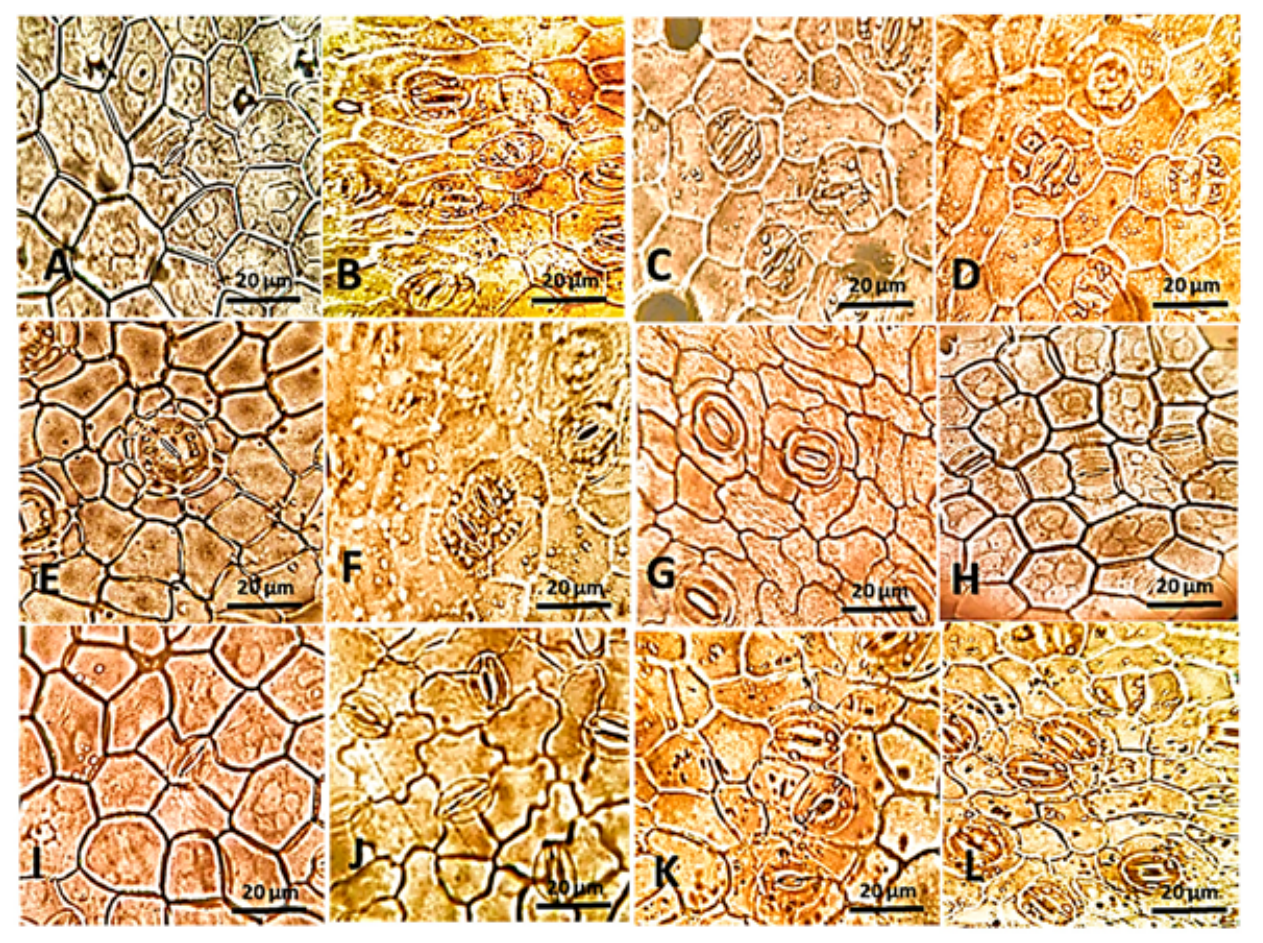

Figure 2. The epidermal surface showing different types and shapes of stomata in the studied Apocynaceous leaves examined by a light microscope at 140×. (A): A. obesum, (B): T. neriifolia, (C): C. procera, (D): D. boliviensis, (E): A. oblongifolia, (F): C. carandas, (G): A. obesum, (H): D. boliviensis, (I): C. procera. (J): T. neriifolia, (K): D. boliviensis, and (L): A. oblongifolia.

The cyclocytic and parallel-shaped associated stomata are investigated in A. oblongifolia and C. carandas (Figure 2E,F respectively), while anisocytic and tetracytic stomata are observed in A. obesum (Figure 2G), as well as hemiparacytic stomata are shown in the most studied plants, such as D. boliviensis (Figure 2H). Hexacytic stomata are shown in C. procera (Figure 2I) and actinocytic stomata are noticed in T. neriifolia (Figure 2J). Finally, stomata associated with middle lamella and V-shaped were investigated in D. boliviensis and A. oblongifolia only (Figure 2K,L, respectively). Moreover, the lower epidermal layer of N. oleander is marked by sunken stomata. The outline of guard cells is elliptical-shaped in most of the studied plants, such as in D. boliviensis (Figure 2F), but it is suborbiculate to orbiculate in 
A. obesum (Figure 2E). The stomatal rim is raised in some of the observed plants, such as in $A$. obesum (Figure 2E), while it is flat with a slit in A. curassavica and C. carandas (Figure $2 \mathrm{H}, \mathrm{K}$, respectively). These observations are in harmony with other Apocynaceae species, where it was reported as anomocytic in Tabernaemontana divaricata [32], Oxystelma esculentum [33] and Hoya soligamiana, while it was reported as sunken cyclocytic in H. incrassate [42]. In this context, Nisa et al. [43] reported stomatal multiplicity in Vincetoxicum arnottianum, where their investigation revealed different stomatal types such as paracytic, anisocytic, tetracytic, actinocytic, anomocytic, laterocytic, stephanocytic, pseudoholoparacytic, and brachyparahexacytic.

\subsubsection{Trichomes}

In the present study, trichomes investigations revealed variations among the studied species, including the presence or absence of hairs, glandular or non-glandular, number of cells that make up hair, and types of the apex (Figure 3, Table S1). The trichomes are indistinct on the lower epidermal layer in D. splendens, but it is observed clearly in the other plants. The non-glandular hairs of the present study are (1) papillate and unicellular with an acute apex as well as bicellular with rounded apex in N. oleander (Figure 3A-C), (2) unicellular with hooked apex in A. obesum (Figure 3D), and (3) multicellular with bent and rounded acute apex in A. curassavica and C. procera (Figure 3E,F). On the other hand, some of the studied plants have glandular hairs, such as A. curassavica and C. procera, whereas they are unicellular and bicellular in A. curassavica (Figure 3G,H), and in C. procera the glandular hairs are multicellular (Figure 3I). In harmony with our results, N. oleander was reported to have a unicellular trichome [15]. The trichomes of Carissa macrocarpa has been reported as non-glandular [13]. Additionally, Mandevilla coccinea trichomes are non-glandular, unicellular, and with acute or round apex [20]. Akyalçın et al. [44] reported that the hairs of Amsonia orientalis are unicellular. Additionally, Gabr et al. [12] investigated 14 species of Apocynaceae and Asclepiadaceae and showed that their trichomes have 15 different types, and some species have glandular hairs, while others have non-glandular ones.
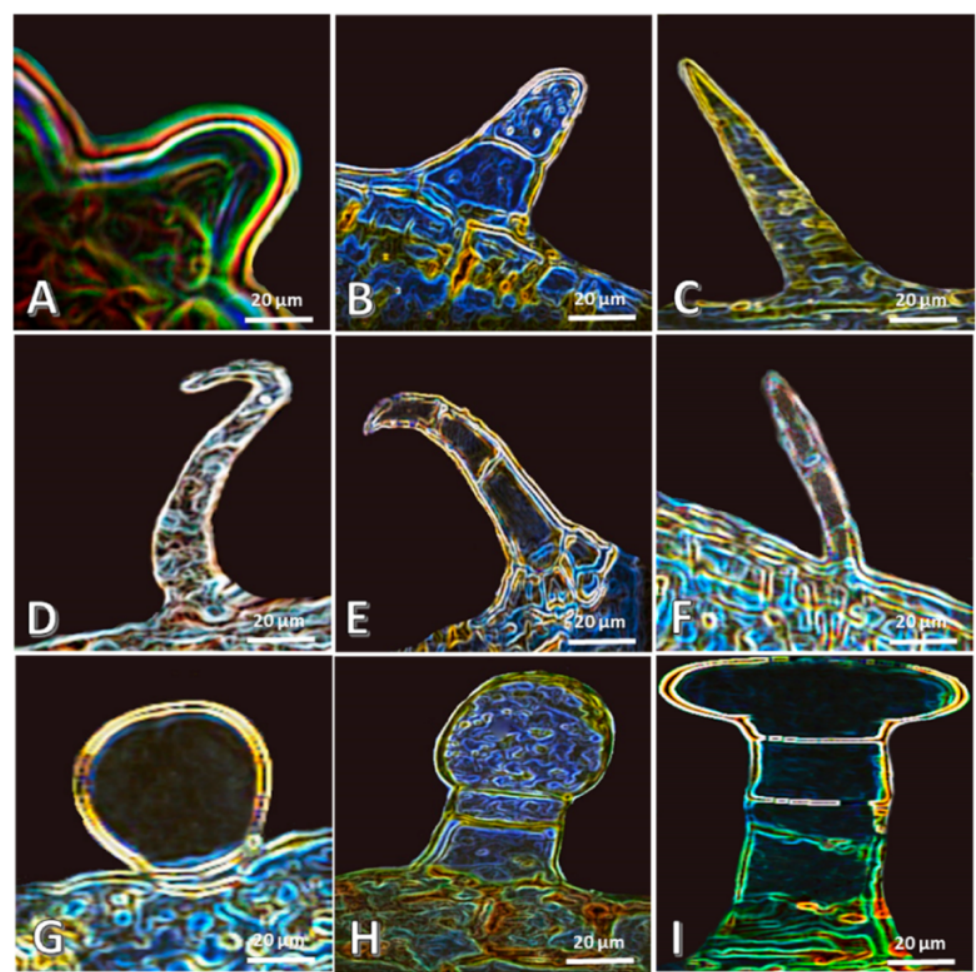

Figure 3. Different trichomes of the studied Apocynaceous plants examined by the light microscope at 140×. (A-C): N. oleander, (D): A. obesum, (E-H): A. curassavica, and (I): C. procera. 


\subsection{Leaf Blade Anatomy}

\subsubsection{Epidermal Layers}

The cuticle layer in some of the studied plants, on the lower epidermis, is thin and smooth, such as in D. boliviensis (Figure 4A), while few studied plants are distinguished with the presence of a thick and rough cuticle layer on lower epidermis, such as N. oleander (Figure 4B). Moreover, the lower epidermal layer is simple in most of the studied plants, such as $C$. carandas (Figure $4 C$ ), while a multi-epidermis is observed in N. oleander and D. boliviensis (Figure 4D). The epidermal tissue of Plumeria rubra and Rauwolfia serpentine has been reported to have a thick cuticle [40]. Similar results are reported by Poornima et al. [33], Duarte and Larrosa [20], and Albert et al. [45], who reported that the epidermis consisted of a single layer and was covered with a thick cuticle in some members of Apocynaceae.

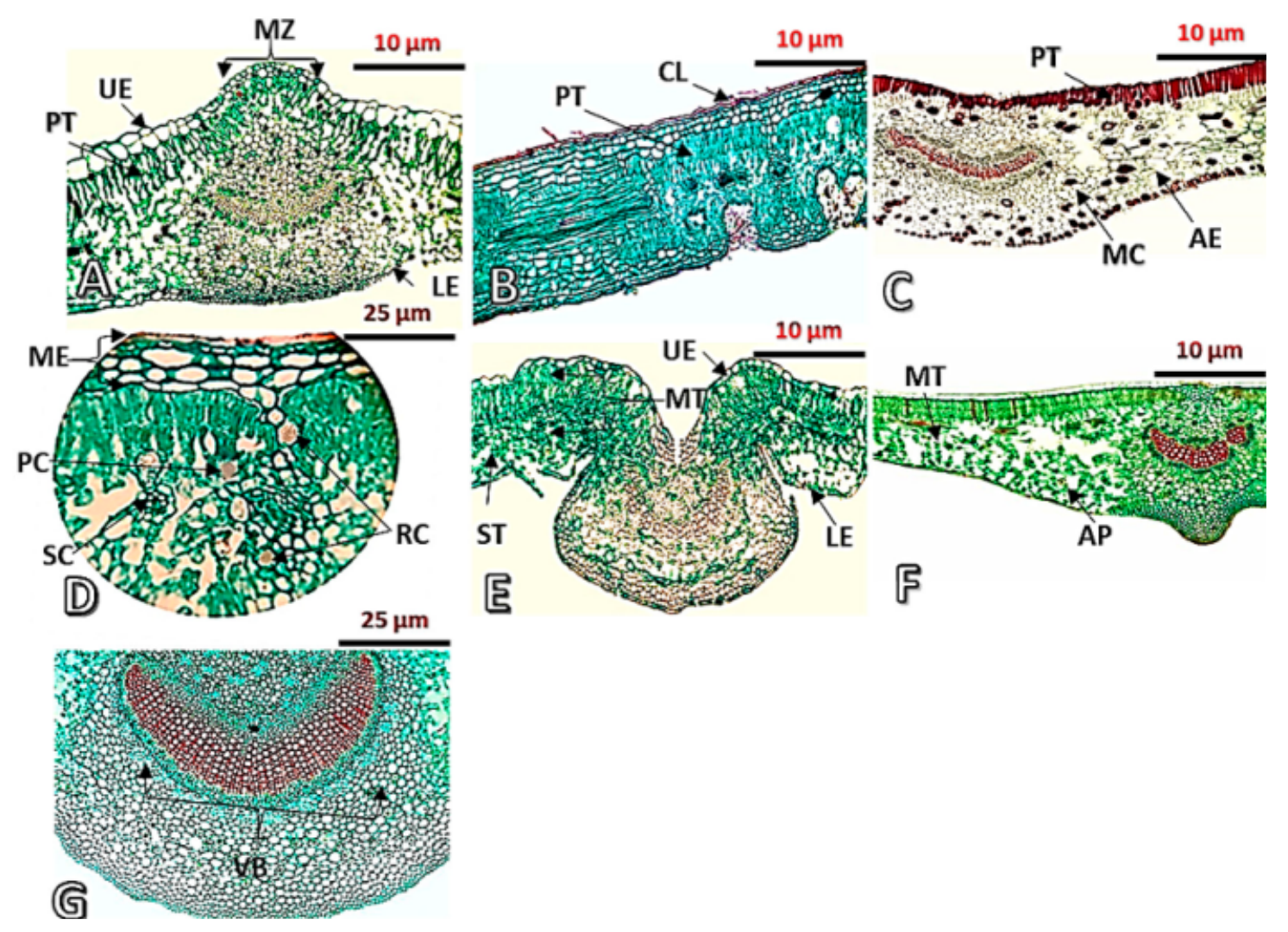

Figure 4. Transverse sections in the leaves of the studied Apocynaceous species taken by light microscope. (A): D. boliviensis (70×), (B): N. oleander (70×), (C): C. carandas (70×), (D): N. oleander (140X), (E): A. curassavica $(70 \times),(\mathbf{F})$ : T. neriifolia $(70 \times),(\mathbf{G}):$. oleander $(70 \times) . A E=$ aerenchyma tissue, $\mathrm{AP}=$ armed parenchyma, $\mathrm{CL}=$ cuticular layer, $\mathrm{LE}=$ lower epidermis, $\mathrm{MC}=$ mucilage cells, $\mathrm{ME}=$ multiepidermis, $\mathrm{MT}=$ mesophyll tissue, $\mathrm{MZ}=$ midrib zone, $\mathrm{PC}=$ prismatic crystals, $\mathrm{PT}=$ palisade tissue, $\mathrm{RC}=$ rosette crystals, $\mathrm{SC}=$ secretory cells, $\mathrm{ST}=$ spongy tissue, $\mathrm{UE}=$ upper epidermis, and $\mathrm{VB}=$ vascular bundle.

\subsubsection{Mesophyll Tissue and Midrib Zone}

The examination of mesophilic tissue revealed anatomical variations among studied plants (Figure 4 and Table S1). The palisade tissue is characterized with the presence of four categories as follows: (1) One layer with monolateral cells and like-palisade cells continued to the midrib zone at the bottom of the upper epidermal layer in some of the studied plants, such as in C. carandas (Figure 4C); (2) multilayers with monolateral cells and like-palisade cells continued to the midrib zone at the bottom of the upper epidermal layer in some of the studied plants, such as in D. boliviensis (Figure 4A); (3) one layer with monolateral cells and like-palisade cells separated to the midrib zone 
at the bottom of the upper epidermal layer in some of the studied plants, such as in A. curassavica (Figure 4E); and (4) multilayers, bilateral, and like-palisade cells separated at the bottom of the upper epidermal layer in the midrib zone in N. oleander (Figure 4B).

Various special contents were observed in the spongy tissue, such as the rosette and prismatic crystals as well as the resin canal in N. oleander leaf (Figure 4D). Additionally, secretory cells are observed in D. boliviensis and C. carandas (Figure 4A,C). A spongy tissue of $C$. carandas is distinguished with the presence of aerenchyma tissue (Figure 4C). Armed tissue is observed in T. neriifolia (Figure 4F). In this context, the spongy tissue of Aspidosperma spruceanum and Pachypodium lamerei has been reported to contain long-armed parenchyma cells [46,47]. The cluster crystals of calcium oxalate have been reported in Carissa macrocarpa [47] and Beaumontia grandiflora [10], while prismatic crystals were observed in Carissa spinarum [10].

The upper surface at the midrib zone is convex in D. boliviensis, but it is concave in A. curassavica (Figure 4A,E), and the midrib zone is straight at the upper surface in T. neriifolia (Figure 4F). All the studied plants showed the presence of concavity at the lower surface except for D. boliviensis (Figure 4A). The aerenchyma tissue is observed in the leaf of $C$. carandas (Figure $4 \mathrm{~F}$ ), while collenchyma tissue prevailed in most of the studied plants (Figure 4).

\subsubsection{Vascular Bundles}

The vascular bundles of the studied species are similar in shape, and they are of a bi-collateral type with a crescent shape (Figure 4); however, they are straight and slightly concave in C. carandas only (Figure 4C). A similar structure of the vascular bundle was investigated in Nerium indicum [48], Mandevilla coccinea [20], and Aspidosperma spruceanum [46].

\subsection{Chemical Attributes}

The chemical composition of the silylated alcoholic extracts of the eight studied Apocynaceae plants (A. obesum, D. boliviensis, C. carandas, N. oleander, A. curassavica, C. procera, A. oblongifolia, and T. neriifolia) are presented in Table 1, and their chromatograms are shown in Figure 5.

Table 1. The relative percentage of silylated metabolites of eight taxa of Apocynaceae derived via GC-MS.

\begin{tabular}{|c|c|c|c|c|c|c|c|c|c|c|}
\hline No. & Compound Name & 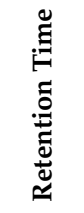 & 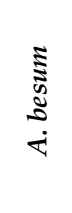 & 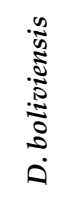 & 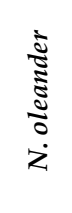 & 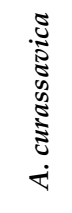 & 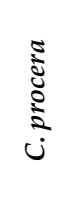 & 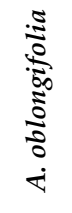 & 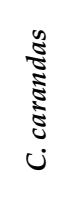 & 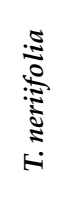 \\
\hline 1 & Propylene glycol & 3.14 & 2.07 & 2.55 & 0.38 & 0 & 1.29 & 0.22 & 0 & 0.16 \\
\hline 2 & $\mathrm{O}, \mathrm{N}$ Bis(3TMS) hydroxyethylamine & 3.67 & 0 & 0 & 0 & 0.81 & 0.8 & 0 & 0 & 0 \\
\hline 3 & $D$-Lactic acid-2TMS & 4.09 & 3.71 & 3.31 & 0.44 & 0.84 & 3.2 & 0 & 0.57 & 0.56 \\
\hline 4 & Alanine-2TMS & 4.83 & 1.27 & 0.37 & 0.17 & 0.96 & 1.12 & 0 & 0.31 & 0.25 \\
\hline 5 & Hydracrylic acid-2TMS & 5.48 & 0 & 4.81 & 0.1 & 0 & 0 & 0 & 0.18 & 0.18 \\
\hline 6 & Benzyl alcohol, TMS & 6.12 & 0.41 & 0 & 0 & 0 & 0.53 & 0 & 0 & 0 \\
\hline 7 & $\mathrm{~N}, \mathrm{O}-2$-TMS-Norvaline & 6.87 & 2.73 & 0.45 & 0.49 & 2.28 & 4 & 0.53 & 0 & 0.41 \\
\hline 8 & Glycerol-3TMS ether & 7.93 & 7.96 & 0.73 & 1.22 & 5.06 & 9.59 & 1.65 & 1.23 & 2.87 \\
\hline 9 & Isoleucine, 2TMS & 8.35 & 1.02 & 0 & 0 & 1.32 & 1.51 & 0 & 0 & 0 \\
\hline 10 & Myristamide & 8.49 & 0.65 & 0 & 0 & 4.12 & 7.32 & 0 & 0 & 0.22 \\
\hline 11 & $\gamma$-Aminobutyric acid-2TMS & 8.67 & 0 & 0 & 0 & 1.43 & 0 & 0 & 0 & 0 \\
\hline 12 & $11-\beta$-Hydroxyandrosterone & 8.84 & 0.52 & 0.88 & 0 & 0 & 0.52 & 0.17 & 0.42 & 0.51 \\
\hline 13 & Glyceric acid, (3TMS) & 9.05 & 0 & 0 & 0 & 0 & 0 & 0 & 0 & 0.26 \\
\hline 14 & Serine 3TMS & 9.6 & 1.19 & 0 & 0 & 0.67 & 0.56 & 0 & 0 & 0 \\
\hline 15 & N,O,O-Tris(3TMS)-L-threonine & 10.03 & 0.86 & 0.43 & 0 & 0.36 & 0 & 0 & 0 & 0 \\
\hline 16 & Homoserine (N,O,O-3TMS) & 11.25 & 0 & 0 & 0 & 0 & 0.44 & 0 & 0 & 0 \\
\hline 17 & $\begin{array}{l}\text { 3-Methyl-5-keto-3-hexenoic acid, } \\
\text { bis(3TMS) }\end{array}$ & 11.46 & 0 & 0 & 0 & 0 & 0 & 0.54 & 0 & 0 \\
\hline 18 & Malic acid-3TMS & 12 & 2.18 & 0.42 & 0 & 0.75 & 1.12 & 0.3 & 0 & 0.51 \\
\hline 19 & L-Threitol, tetrakis(3TMS) ether & 12.12 & 0.69 & 0.52 & 0 & 0.52 & 1.3 & 0 & 0 & 0.2 \\
\hline
\end{tabular}


Table 1. Cont.

\begin{tabular}{|c|c|c|c|c|c|c|c|c|c|c|}
\hline No. & Compound Name & 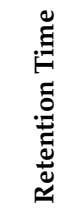 & 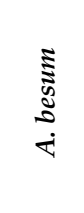 & 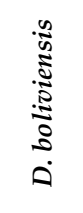 & 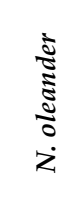 & 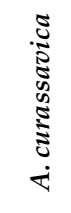 & 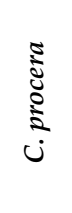 & 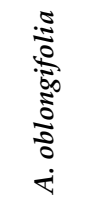 & 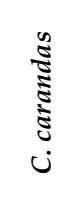 & 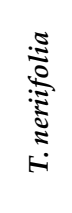 \\
\hline 20 & Pimelic acid (2TMS) & 12.53 & 0 & 0 & 0 & 0 & 0 & 0.19 & 0 & 0 \\
\hline 21 & Pyroglutamic acid, bis(3TMS)- & 12.75 & 0 & 0 & 0 & 0.88 & 1.07 & 0 & 0 & 0.48 \\
\hline 22 & Cystathionine, 2TMS & 13.1 & 0 & 0 & 0 & 0 & 0 & 0 & 0 & 0.19 \\
\hline 23 & $\begin{array}{l}D \text {-(+)-Ribono-1,4-lactone, } \\
\text { tris(3TMS) ether }\end{array}$ & 13.47 & 0.57 & 0 & 0.21 & 0 & 0 & 0 & 0 & 0 \\
\hline 24 & $\begin{array}{l}\text { Asparagine, } N, N, N^{\prime} \text {-tris(3TMS)-', } \\
\text { 3TMS ester }\end{array}$ & 14.17 & 1.53 & 0 & 0 & 0.93 & 4.02 & 0 & 0 & 0 \\
\hline 25 & Glutamic acid (3TMS) & 14.4 & 0 & 0 & 0 & 0.57 & 1.48 & 0 & 0 & 0 \\
\hline 26 & Aasparagine-3TMS & 15.13 & 0 & 0 & 0 & 0.85 & 0 & 0 & 0 & 0.16 \\
\hline 27 & D-Pinitol, pentakis(3TMS) ether & 15.37 & 0 & 0 & 0 & 0 & 0 & 0.32 & 28.87 & 0 \\
\hline 28 & Cystathionine-2TMS & 15.44 & 0.67 & 0 & 0 & 0 & 0 & 0 & 0 & 0 \\
\hline 29 & $L-(-)$-Arabitol, pentakis(3TMS) ether & 15.52 & 2.45 & 0.7 & 0 & 6.21 & 0.88 & 0 & 0.24 & 0.17 \\
\hline 30 & Erythrose-3TMS & 15.82 & 3.97 & 0 & 0.69 & 0.98 & 1.41 & 0.22 & 0.5 & 0 \\
\hline 31 & $\begin{array}{l}D \text {-(-)-Fructopyranose, pentakis(3TMS) } \\
\text { ether (isomer 2) }\end{array}$ & 16.95 & 3.67 & 7.15 & 8.02 & 5.21 & 2.81 & 12.11 & 1.3 & 4.72 \\
\hline 32 & $\begin{array}{l}\text { Glucofuranoside, methyl } \\
\text { 2,3,5,6-tetrakis-O-(3TMS)-, } \alpha \text {-D- }\end{array}$ & 17.51 & 0 & 0 & 0.38 & 0.51 & 0 & 0.54 & 1.17 & 1.11 \\
\hline 33 & Quinic acid-5TMS & 17.64 & 14.5 & 17.86 & 1.2 & 0.36 & 0.99 & 8.85 & 15.1 & 16.19 \\
\hline 34 & $\begin{array}{l}\beta \text {-D-(+)-Mannopyranose, } \\
\text { pentakis(3TMS) ether }\end{array}$ & 18.18 & 0.94 & 0 & 3.71 & 0.79 & 1.49 & 5.79 & 1.2 & 0 \\
\hline 35 & $\begin{array}{l}\text { 1,5-Anhydro- } D \text {-sorbitol, tetrakis(3TMS) } \\
\text { ether }\end{array}$ & 18.23 & 0.93 & 2.11 & 0 & 0 & 0 & 0 & 0 & 20.04 \\
\hline 36 & $\begin{array}{l}\text { D-Mannitol, } \\
\text { 1,2,3,4,5,6-hexakis-O-(3TMS)- }\end{array}$ & 18.53 & 1.43 & 0.79 & 0.12 & 0.43 & 0.72 & 0 & 0.19 & 0.94 \\
\hline 37 & $\begin{array}{l}\text { Xylopyranose, } \\
\text { 3-O-methyl-1,2,4-tris-O-(3TMS)- }\end{array}$ & 18.69 & 1.81 & 1.01 & 8.36 & 0 & 0 & 2.54 & 1.01 & 0 \\
\hline 38 & $\alpha$-D-Glucopyranosiduronic acid, TMS & 18.90 & 0 & 0.66 & 0.41 & 0 & 0 & 0 & 0.21 & 4.51 \\
\hline 39 & $\beta$-D-Glucopyranosiduronic acid & 19.13 & 0 & 0.65 & 0.52 & 1.95 & 0.44 & 0.19 & 0 & 1.2 \\
\hline 40 & $\beta$-D-Glucopyranose, TMS & 19.49 & 0.62 & 4.85 & 5.63 & 4.69 & 1.06 & 9.63 & 0.55 & 3.62 \\
\hline 41 & D-Pinitol, pentakis(3TMS) ether & 19.59 & 12.82 & 4.35 & 6.25 & 2.33 & 1.33 & 22.08 & 8.43 & 28.84 \\
\hline 42 & $\begin{array}{l}\beta \text {-D-Arabinopyranose, } \\
\text { 1,2,3,4-tetrakis-O-(3TMS)- }\end{array}$ & 19.8 & 0 & 0 & 0.11 & 2.14 & 0 & 0 & 0 & 0.37 \\
\hline 43 & Myoinositol-TMS & 20.81 & 4.56 & 1.86 & 0.69 & 3.74 & 4.72 & 0.99 & 0.19 & 0 \\
\hline 44 & $\begin{array}{l}\beta \text {-D-Arabinopyranose, } \\
\text { 1,2,3,4-tetrakis-O-(3TMS) }\end{array}$ & 21.83 & 0 & 0.47 & 0 & 0.4 & 0.63 & 0 & 0 & 0 \\
\hline 45 & Bis (3TMS) derivative of nonamide & 22.2 & 0 & 1.08 & 0 & 1.61 & 2.18 & 0.5 & 0.39 & 0.24 \\
\hline 46 & $D$-(+)-Glucosamine & 23.44 & 2.09 & 2.22 & 0 & 0.79 & 1.16 & 0.25 & 0.49 & 0 \\
\hline 47 & Glucosamine per-TMS & 24.31 & 1.4 & 4.41 & 0.15 & 6.71 & 8.9 & 2.51 & 1.58 & 0.75 \\
\hline 48 & 2,2-Dideutero-nonyl-3TMS ether & 24.62 & 0 & 0 & 0 & 0.83 & 0.99 & 0.36 & 0.21 & 0 \\
\hline 49 & Oleamide, $N$-3TMS & 25.51 & 6.69 & 10.6 & 5.38 & 5.17 & 6.13 & 1.88 & 4.89 & 0.86 \\
\hline 50 & Tetradecanamide, $N$-5TMS & 25.83 & 0.85 & 1.59 & 0 & 0.63 & 1.01 & 0.22 & 0.46 & 0 \\
\hline 51 & Aucubin, hexakis(3TMS) ether & 26.08 & 0 & 3.28 & 8.39 & 7.18 & 0 & 4.1 & 4.04 & 1.63 \\
\hline 52 & cis-13-Eicosenoic acid & 26.63 & 1.19 & 2.89 & 2 & 1.45 & 3.64 & 0.5 & 1.69 & 0 \\
\hline 53 & $D$-(+)-Turanose, octakis(3TMS) ether & 26.83 & 0 & 6.69 & 6.56 & 9.07 & 0.47 & 3.55 & 5.64 & 0.95 \\
\hline 54 & Sucrose, octakis(3TMS) ether & 27.27 & 1.44 & 4.34 & 27.33 & 6.75 & 9.2 & 10.99 & 6.2 & 3.01 \\
\hline 55 & $D$-(+)-Turanose, octakis(3TMS) ether & 27.43 & 0 & 1.35 & 4.81 & 1.87 & 0 & 2.42 & 0.99 & 0.24 \\
\hline 56 & 1-Monostearin-2TMS & 29.31 & 2.62 & 0 & 0.99 & 0.84 & 2.38 & 0.41 & 1.28 & 0.68 \\
\hline 57 & dl-6-Thioctic amide, $N$-3TMS & 29.9 & 1.54 & 0 & 0.22 & 1.51 & 1.52 & 0.8 & 2.34 & 0 \\
\hline 58 & Friedelan-3-TMS & 31.06 & 0 & 0 & 0 & 0 & 0 & 0 & 3.39 & 0 \\
\hline 59 & 1-Monolinoleoylglycerol-3TMS ether & 32.81 & 0.45 & 0 & 0.24 & 0 & 2.34 & 0.27 & 0.98 & 0.58 \\
\hline 60 & Quercetin $7,3^{\prime}, 4^{\prime}$-trimethoxy-2TMS & 33.84 & 0.71 & 0 & 0 & 0 & 0.58 & 0 & 0 & 0 \\
\hline 61 & 1-Monolinoleoylglycerol-3TMS ether & 34.06 & 0.64 & 0 & 0 & 0 & 0.65 & 0.17 & 0 & 0 \\
\hline 62 & $\beta$-Sitosterol, 3TMS ether & 34.71 & 1.22 & 0.26 & 0.16 & 0.73 & 1.18 & 0.22 & 0.4 & 0.53 \\
\hline 63 & $\beta$-Amyrin-3TMS ether & 35.02 & 0.64 & 0 & 0.1 & 0.45 & 0 & 0.55 & 0.4 & 0.6 \\
\hline Total & & & 97.2 & 95.6 & 95.4 & 97.7 & 98.7 & 96.6 & 97 & 98.7 \\
\hline
\end{tabular}


Several compounds were reported from these plants such as cardenolide, triterpenoids, pregnanes, carbohydrate, phenolic acids, flavonoids, and amino acids [49]. The previous chemical studies deduced that $A$. obesum is a very rich plant with different compounds, including flavonoids triterpenes, pregnanes, cardenolides, cardiac glycosides, and carbohydrate [49]. The gas chromatography-mass spectroscopy (GC-MS) analysis of the silylated methanolic extract of $A$. obesum showed the presence of forty compounds (Table 1).

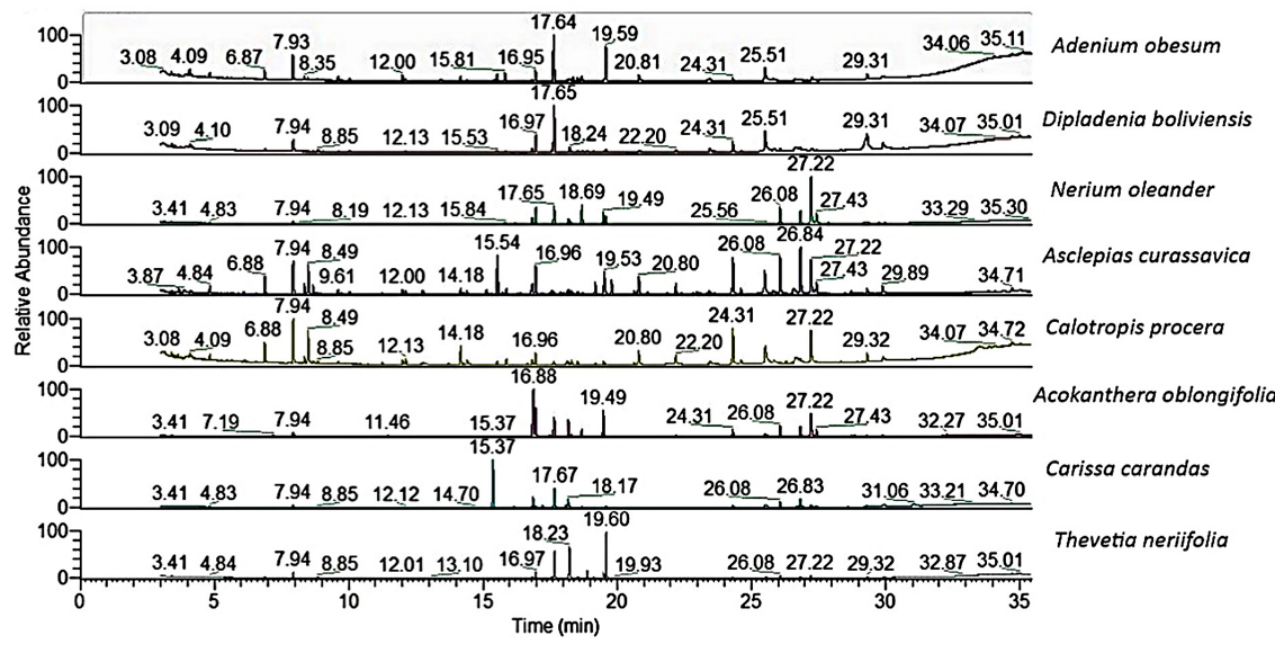

Figure 5. The GC-MS chromatograms of the chemical compounds of the studied Apocynaceae species.

Quinic acid-5TMS (14.50\%), D-pinitol-3TMS (12.82\%), glycerol-3TMS (7.96\%), oleamide- $N$-3TMS (6.69\%), myoinositol-TMS (4.56\%), erythrose-3TMS (3.97\%), D-(-)-fructopyranose-3TMS (isomer 2) $(3.67 \%)$, and myoinositol TMS $(3.32 \%)$ were identified as the main compounds. From all identified compounds, the phenolic compounds, quinic acid, and glycerol were the main compounds of this plant along with the abundance of amino acids and sugars.

The GC-MS analysis of the silylated methanolic extract of $D$. boliviensis revealed the presence of thirty-three compounds (Table 1). Quinic acid-5TMS (17.86), oleamide- $N$-3TMS $(10.60 \%)$, $D$-(-)-fructopyranose-3TMS (isomer 2) (7.15\%), $D$-(+)-turanose-3TMS (6.69\%), $\beta$-D-glucopyranose-TMS $(4.85 \%)$, hydracrylic acid-2TMS (4.81\%), glucosamine per-TMS $(4.41 \%)$, sucrose-3TMS $(4.34 \%)$, $D$-lactic acid-2TMS (3.31), aucubin-3TMS (3.28\%), D-pinitol-3TMS (2.98), and cis-13-eicosenoic acid-TMS (2.89\%) were characterized as the majors of all identified constituents. As described in A. obesum, quinic acid was found as a preponderance phenolic acid in D. boliviensis, in addition to amino acids and sugars.

Vikas and Payal [50] showed that N. oleander contained several constituents such as cardenolides triterpenoids, and carbohydrates. In the present study, thirty-two silylated compounds were assigned from the silylated methanolic extract of $N$. oleander (Table 1). Out of these compounds, sucrose-3TMS (27.33\%), aucubin-3TMS (8.39\%), xylopyranose-3-O-methyl-3TMS (8.36\%), D-(-)-fructopyranose-3TMS (isomer 2) $(8.02 \%), D$-(+)-turanose-3TMS (6.56\%), $\beta$-D-glucopyranose-TMS (5.63\%), oleamide- $N$-3TMS (5.38\%), $D$-(+)-turanose-3TMS (4.81\%), $D$-pinitol-3TMS (4.35\%)), and $\beta$ - $D$-(+)-mannopyranose-3TMS $(3.71 \%)$ were characterized as the main constituents of this plant. In complete contrast with the two previous plants (A. obesum and D. boliviensis), the polysaccharide, sucrose, as well as the iridoid glycoside, aucubin, alongside with amino acids and sugars, were determined as the main compounds in N. oleander.

The A. curassavica was described as a promising resource of seco-triterpenoids, pregnanes, glycosides, cardenolides, and flavonoids [51-53]. Forty-three silylated constituents were assigned as overall constituents of the methanolic extract of A. curassavica (Table 1). From all identified compounds, $D$-(+)-turanose-3TMS (9.07\%), aucubin-3TMS (7.18\%), sucrose-3TMS $(6.75 \%)$, glucosamine per-TMS (6.71\%), L-(-)-arabitol-3TMS (6.21\%), D-(-)-fructopyranose-3TMS (isomer 2) (5.21\%), oleamide-N-3TMS (5.17\%), glycerol-3TMS (5.06\%), $\beta$-D-glucopyranose-TMS (4.69\%), and myristamide-TMS $(4.12 \%)$ were 
found to be the major components. In contrast with A. obesum and D. boliviensis, and in complete agreement with $N$. oleander, the reduced disaccharide, turanose, and the iridoid glycoside, aucubin, were found as the main compounds in addition to an abundance of sugars and amino acids.

The different parts of $C$. procera have been characterized by a high content of cardiac glycoside, triterpenoids, pregnanes, and their glycosides, as well as phenolics and flavonoids [34]. In the present study, forty-two silylated compounds were identified in the methanolic extract of $C$. procera (Table 1 ). Glycerol-3TMS $(9.59 \%)$, sucrose-3TMS $(9.20 \%)$, glucosamine per-TMS $(8.90 \%)$, myristamide-TMS (7.32\%), oleamide- $N-3$ TMS (6.13\%), norvaline- $N, \mathrm{O}-2 \mathrm{TMS}$ (4.00\%), myoinositol-TMS (4.72\%), asparagine, $N, N, N^{\prime}$-tris(3TMS)- (4.02\%), myoinositol TMS (3.81\%), and cis-13-eicosenoic acid-TMS (3.64\%) were assigned as the main identified constituents. The glyceride compound, glycerol, and the polysaccharide, sucrose, were found as the major compounds, as well as other major compounds of sugars, amino acids, and fatty acids. This results exhibited a strong agreement with the chemical constituents of the above four plants.

From the GC-MS of the silylated methanolic extract of A. oblongifolia, thirty-four compounds were identified (Table 1). The sugars, $D$-pinitol-3TMS (22.08\%), $D$-(-)-fructopyranose-3TMS (isomer 2) $(12.11 \%)$, sucrose-3TMS (10.99\%), $\beta$-D-glucopyranose-TMS $(9.63 \%), \beta$ - $D-(+)$-mannopyranose-3TMS $(5.79 \%), D-(+)$-turanose-3TMS (3.55\%), and $D-(+)$-turanose-3TMS $(2.42 \%)$, the phenolic acid, quinic acid-5TMS $(8.85 \%)$, the iridoid glycoside, aucubin-3TMS (4.10\%), in addition to glucosamine per-TMS $(2.51 \%)$, were characterized as the main compounds. These results support the fact that $A$. oblongifolia is correlated to all the above plants, especially A. obesum and D. boliviensis, where it is characterized with a preponderance of sugars, phenolic acids, iridoid glycoside, and amino acids.

Cardiac glycosides, triterpenoids, flavonoids, saponins, tannins, steroids, and sesquiterpenes were characterized in the different parts of C. carandas [28]. Herein, thirty-two components were characterized via the GC-MS analysis of the silylated methanolic extract of $C$. carandas (Table 1). Quinic acid-5TMS (15.10\%), D-pinitol-3TMS (8.43\%), sucrose-3TMS (6.20\%), D-(+)-turanose-3TMS $(5.64 \%)$, oleamide- $N$-3TMS $(4.89 \%)$, aucubin-3TMS (4.04\%), and friedelan-3-TMS (3.39\%) were determined as the major compounds. These results support the strong engagement between this plant and both A. oblongifolia as well as A. obesum, with a preponderance of pinitol and quinic acid. Additionally, the relationship of this plant with the other plants was supported via the abundance of sugars, phenolic acids, iridoid glycoside, and amino acids.

Several metabolites, such as triterpenes, cardiac glycosides, cardenolide, iridoid-glucosides, and sterols were isolated and identified from different parts of T. neriifolia [54]. In our work, thirty-five components were characterized via the GC-MS analysis of the silylated methanolic extract of T. neriifolia (Table 1). D-Pinitol-3TMS (28.84\%), 1,5-anhydro-D-sorbitol-3TMS (20.04\%), quinic acid-5TMS (16.19\%), D-(-)-fructopyranose-3TMS (isomer 2) (4.72\%), $\alpha$-D-glucopyranosiduronic acid-TMS (4.51\%), $\beta$-D-glucopyranose-TMS (3.62\%), sucrose-3TMS (3.01\%), and glycerol-3TMS (2.87\%) were identified as the main components of the overall identified constituents. These results showed that this plant is not correlated with the other plants, A. oblongifolia, A. obesum, and C. carandas, with a generous amount of sugars, phenolic acids, and amino acids, especially pinitol and quinic acid. In addition, the relationship of this plant with the other plants was supported via the abundance of a majority of sugars, phenolic acids, and amino acids.

From the previous chemical characterization of these eight plants, a significant correlation was observed among them. Akin to the previous studies, all of these plants are very rich with the same chemical metabolites, especially cardiac glycosides, cardenolide, triterpenoids, sugars, phenolic acids, and amino acids. Our results supported this theory of correlation, via the characterized compounds from the GC-MS analysis of the silylated forms of the alcoholic extracts, which showed the abundance of the phenolic acids, amino acids, and sugars. Additionally, in full agreement with the previously described compounds, the steroidal compound, $\beta$-sitosterol-3TMS ether, and the triterpenoidial, $\beta$-amyrin-3TMS ether, were identified from these plants [29]. Correspondingly, the flavonoid, quercetin $7,3^{\prime}, 4^{\prime}$-trimethoxy-2TMS, was found in A. besum and C. procera. 


\subsection{Correlation Analysis of the Studied Apocynaceae Species}

\subsubsection{Principal Component Analysis (PCA) Based on the Chemical Composition}

Although different non-volatile patterns were observed by simple visual inspection of the GC-MS chromatograms (Figure 5, Table 1), the data of the chemical compounds were subjected to PCA in an attempt to assess the variance within plants in an untargeted manner.

The PCA is an unsupervised clustering method, requiring no knowledge of the data set, which acts to reduce the dimensionality of multivariate data while preserving variance within the data [37]. The correlations among the eight species under study concerning the major components were analyzed based on PCA (Figure 6A, Table S2). The PCA horizontal axis explained $38.74 \%$ of the total variance, with the vertical axis explaining a further $21.43 \%$.

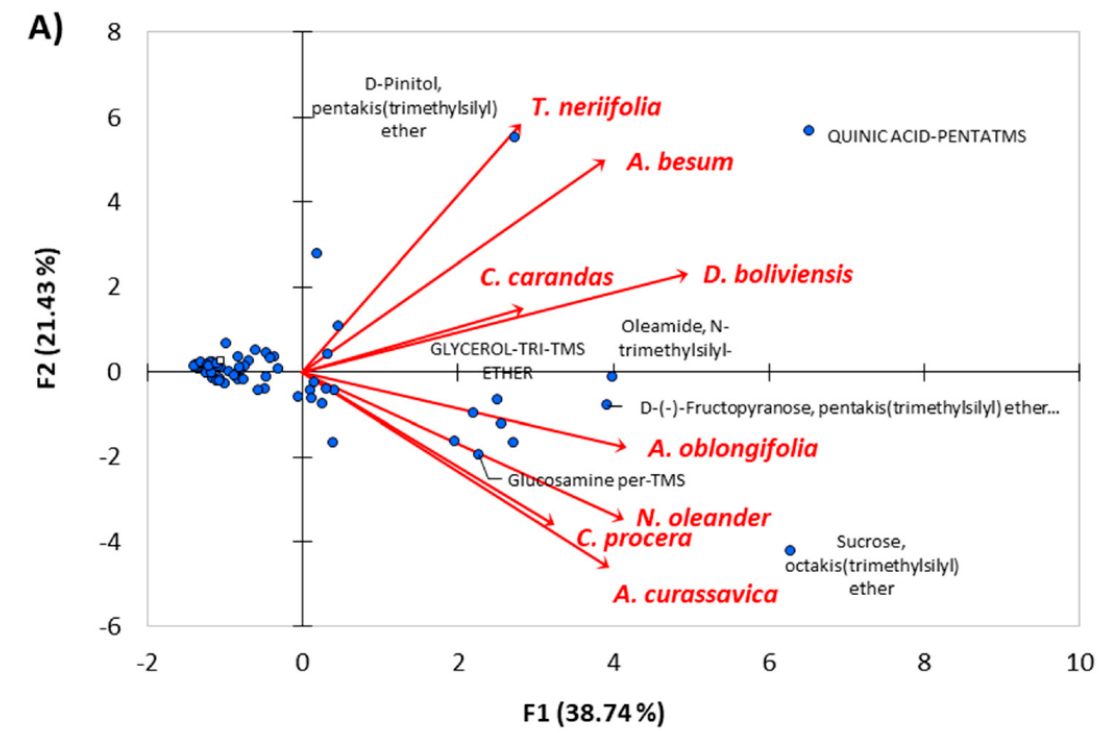

B)
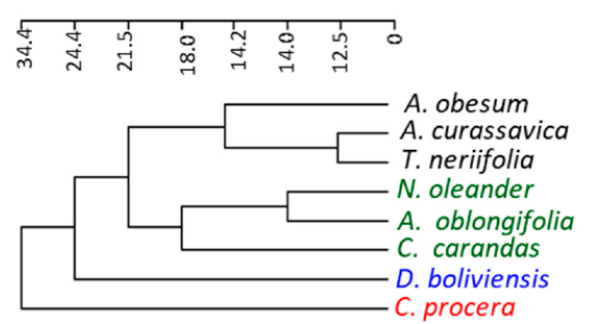

C)
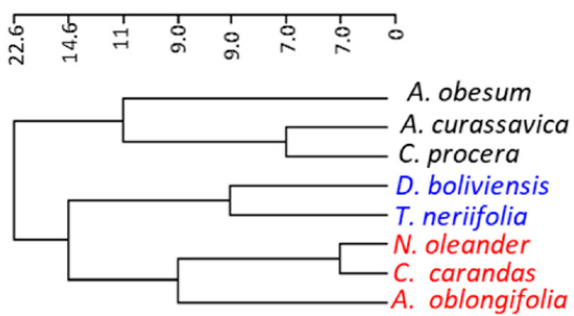

D)
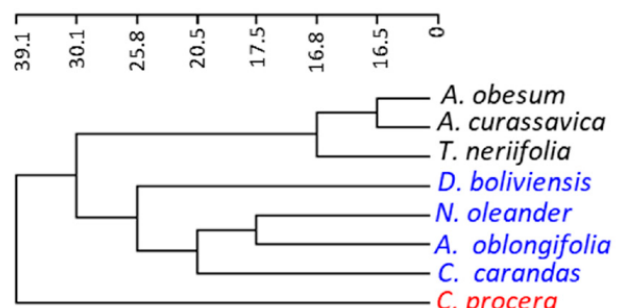

Figure 6. Correlation analysis of the studied Apocynaceae species. (A) Principal component analysis (PCA) based on the chemical composition; (B) hierarchical clustering (Ward's method to the Euclidean distances) based on macro-, micro-morphological, and anatomical characteristics; (C) cluster analysis of chemical characteristics; and (D) cluster analysis of all merged parameters. 
The results deduced the correlations among the eight plant species; all of these plants were located on the positive side of the cluster. On further analysis of the results, the A. curassavica, and C. procera exhibited very strong correlations based upon the abundance of the sugars and amino acids, especially the major compounds sucrose, glucosamine, oleamide, and others. In the same way, A. obesum and $D$. boliviensis have a significant correlation between each other in terms of their richness in quinic acid, oleamide, and fructopyranose, in addition to the other sugars and amino acids. Furthermore, the correlations between A. curassavica, C. procera, A. obesum, and D. boliviensis were found by the abundance of sugars and amino acids. N. oleander was strongly correlated with A. oblongifolia via the superiority of sucrose, $D$-(-)-fructopyranose, and $\beta$ - $D$-glucopyranose, as well as other majors of sugars and amino acids. The two plants, T. neriifolia and C. carandas, showed remarkable correlation via some major constituents, such as pinitol and quinic acid, in addition to sugars, phenolic acids, and amino acids. In a general conclusion of this point, the eight plants under investigation were deduced to have a significant chemical correlation with the presence of sugars and amino acids as well as phenolic acids and iridoid glycosides.

\subsubsection{Cluster Analysis of the Eight Species}

The application of the hierarchical cluster analysis revealed different clustering between the anatomical, morphological, and chemical parameters (Figure 6). Based on the 80 morphological and anatomical characters, the application of the hierarchical cluster analysis revealed the separation of C. procera and D. boliviensis from other plants. However, A. obesum, A. curassavica, and T. neriifolia were grouped together, while N. oleander, A. oblongifolia, and C. carandas were grouped in another group, and these two are relatively related to each other (Figure 6B). On the other hand, the hierarchical cluster analysis based on the chemical parameters (63 chemical compounds) showed three clusters. The first cluster includes A. obesum, A. curassavica, and C. procera (Figure 6C); the second cluster contains D. boliviensis and T. neriifolia; while the third cluster consists of N. oleander, C. carandas, and A. oblongifolia.

By merging all parameters (anatomical, morphological, and chemical parameters), the cluster analysis is similar to the morphological and anatomical cluster (Figure 6D), and three clusters were observed. The first cluster comprises A. obesum, A. curassavica, and T. neriifolia; while the second cluster contains D. boliviensis, N. oleander, A. oblongifolia, and C. carandas; and the third cluster consists of $C$. procera alone (Figure 6D). This clustering is inconsistent with the classification of Endress and Bruyns [2] and Endress et al. [3], where they classified A. obesum under subfamily Apocynoideae with a close relation to $N$. oleander, while the present data showed that it is closely related to the members of Asclepiadoideae (A. curassavica and C. procera).

Regarding C. procera, the cluster analysis based on chemical composition showed consistency with the findings of Endress and Bruyns [2] and Endress et al. [3], in contrast with anatomical and morphological data. All clusters showed a close relation between N. oleander and A. oblongifolia, although this observation is inconsistent with the classification of Endress and Bruyns [2] and Endress et al. [3].

\section{Conclusions}

The interlacing of morphological, anatomical, and chemical characters of the leaf characters of the eight studied Apocynaceae species revealed substantial variation among species. Moreover, the cluster analysis, based on all merged characters, showed that the eight species can be categorized into three clusters. The first cluster comprises A. obesum, A. curassavica, and T. neriifolia; while the second cluster contains D. boliviensis, N. oleander, A. oblongifolia, and C. carandas; and the third cluster consists of $C$. procera alone. This cluster revealed some similarities to the classification of Endress and Bruyns [2] and Endress et al. [3], while it showed inconsistency regarding A. obesum, C. procera, and $N$. oleander, since the present results showed that $A$. obesum is closely related to the Asclepiadoideae species, and C. procera is separated alone, while N. oleander showed a relationship to the species of Rauvolfioideae. Due to this inconsistency and the distinguished variation among the studied 
plants, further study is recommended for more characterization of the studied plants, based on more parameters, including molecular characterization, particularly of A. obesum, C. procera, and N. oleander.

Supplementary Materials: The following are available online at http://www.mdpi.com/1424-2818/12/9/334/s1, Figure S1: Leaf morphology of the studied Apocynaceae plants, Table S1: List of different characters of the eight studied Apocynaceae plants, Table S2: Correlations between variables and factor loadings of PCA.

Author Contributions: Conceptualization, A.M.E.-T., A.E.-N.G.E.G., A.I.E., and A.M.A.-E.; investigation, A.M.E.-T., A.E.-N.G.E.G., A.I.E., and A.M.A.-E.; methodology, A.M.E.-T. and A.E.-N.G.E.G.; funding acquisition, J.A.; writing-original draft, A.M.E.-T., A.E.-N.G.E.G., A.I.E., and A.M.A.-E.; writing-review and editing, A.M.E.-T., A.E.-N.G.E.G., A.I.E., A.M.A.-E., and J.A. All authors have read, revised, and agreed to the published version of the manuscript.

Funding: Researchers supporting project number (RSP-2020/193) King Saud University, Riyadh, Saudi Arabia, and the APC was funded also by the same project at King Saud University.

Acknowledgments: The authors extend their appreciation to the Department of Agricultural Botany, Faculty of Agriculture, Al-Azhar University, Cairo, Egypt, and the National Research Centre, Egypt. Additionally, authors extend their appreciation to the researchers supporting project number (RSP-2020/193) King Saud University, Riyadh, Saudi Arabia.

Conflicts of Interest: The authors declare no conflict of interest.

\section{References}

1. Brown, R. On the Asclepiadeae. Preprinted from 1811, Mem. Wernerian Nat. Hist. Soc. 1810, 1, 12-78.

2. Endress, M.E.; Bruyns, P.V. A revised classification of the Apocynaceae s.l. Bot. Rev. 2000, 66, 1-56. [CrossRef]

3. Endress, M.E.; Liede-Schumann, S.; Meve, U. An updated classification for Apocynaceae. Phytotaxa 2014, 159, 175-194. [CrossRef]

4. Judd, W.S.; Sanders, R.W.; Donoghue, M. Angiosperm family pairs: Preliminary phylogenetic analyses. Harv. Pap. Bot. 1994, 5, 1-51.

5. Struwe, L.; Albert, V.A.; Bremer, B. Cladistics and family level classification of the Gentianales. Cladistics 1994, 10, 175-206. [CrossRef]

6. Civeyrel, L.; Le Thomas, A.; Ferguson, K.; Chase, M.W. Critical Reexamination of palynological characters used to delimit Asclepiadaceae in comparison to the molecular phylogeny obtained from plastidmatk sequences. Mol. Phylogenet. Evol. 1998, 9, 517-527. [CrossRef] [PubMed]

7. Potgieter, K.; Albert, V.A. Phylogenetic relationships within Apocynaceae sl based on trnL intron and trnL-F spacer sequences and propagule characters. Ann. Missouri Bot. Gard. 2001, 88, 523-549. [CrossRef]

8. Boulos, L. Flora of Egypt (Vol. 2); Al Hadara Publishing: Cairo, Egypt, 2000.

9. Tackholm, V. Students' Flora of Egypt, 2nd ed.; Cairo University Press.: Cairo, Egypt, 1974.

10. El-fiki, M.A.; El-Taher, A.M.; EL-Gendy, A.G.; Lila, M.I. Morphological and anatomical studies on some taxa of family Apocynaceae. Al-Azhar J. Agric. Res. 2019, 44, 136-147.

11. El-fiki, M.A.; Hamz, M.K. Normal and abnormal stomatal features in some magnoliophyta. Ann. Agric. Sci. Aim Shams Univ. 1984, 29, 581-593.

12. Gabr, D.G.; Khafagi, A.A.F.; Mohamed, A.H.; Mohamed, F.S. The significance of leaf morphological characters in the identification of some species of Apocynaceae and Asclepiadaceae. J. Am. Sci. 2015, 11, 61-70.

13. Khan, D. Some morphological observations on leaves of Carissa macrocarpa (eckl.) A. DC.(family Apocynaceae). Int. J. Biol. Biotechnol. 2019, 16, 1027-1045.

14. Aguoru, C.; Abah, O.; Olasan, J. Systematic descriptions and taxonomic studies on three species of Plumeria in North Central Nigeria. Int. J. Innov. Sci. Res. 2015, 17, 403-411.

15. Abdalla, M.M.; Eltahir, A.S.; El-Kamali, H.H. Comparative morph-anatomical leaf characters of Nerium oleander and Catharanthus roseus family (Apocynaceae). Eur. J. Basic Appl. Sci. 2016, 3, 68-73.

16. Kapoor, S.; Mitra, R. Epidermal and venation studies in Apocynaceae-VI. Nelumbo 1979, 21, 68-80.

17. Al-Massarani, S. Pharmacognostical and Biological Study of Caralluma Sinaica Growing in Saudi Arabia; King Saud University, Faculty of Pharmacy: Riyadh, Saudi Arabia, 2011.

18. Camargo, M.A.B.; Marenco, R.A. Density, size and distribution of stomata in 35 rainforest tree species in Central Amazonia. Acta Amazon. 2011, 41, 205-212. [CrossRef] 
19. Inamdar, J.; Patel, R.; Mohan, J. Structure and ontogeny of stomata in vegetative and floral organs of some Apocynaceae. Feddes Repert. 1991, 102, 409-423. [CrossRef]

20. Duarte, M.d.R.; Larrosa, C.R.R. Morpho-anatomical characters of the leaf and stem of Mandevilla coccinea (Hook. et Arn.) Woodson, Apocynaceae. Braz. J. Pharm. Sci. 2011, 47, 137-144.

21. Broyles, S.B.; Wyatt, R. Allozyme diversity and genetic structure in southern Appalachian populations of poke milkweed. Asclepias exaltata. Syst. Bot. 1993, 18, 18-30. [CrossRef]

22. Edwards, A.L.; Wyatt, R. Population genetics of the rare Asclepias texana and its widespread sister species, A. Perennis. Syst. Bot. 1994, 19, 291-307. [CrossRef]

23. Tada, F.; Yamashiro, T.; Maki, M. Development of microsatellite markers for the endangered grassland perennial herb Vincetoxicum atratum (Apocynaceae-Asclepiadoideae). Conserv. Genet. 2009, 10, 1057-1059. [CrossRef]

24. Kabat, S.M.; Dick, C.W.; Hunter, M.D. Isolation and characterization of microsatellite loci in the common milkweed, Asclepias syriaca (Apocynaceae). Am. J. Bot. 2010, 97, e37-e38. [CrossRef] [PubMed]

25. Nakahama, N.; Kaneko, S.; Hayano, A.; Isagi, Y.; Inoue-Murayama, M.; Tominaga, T. Development of microsatellite markers for the endangered grassland species Vincetoxicum pycnostelma (Apocynaceae) by using next-generation sequencing technology. Conserv. Genet. Resour. 2012, 4, 669-671. [CrossRef]

26. Yamashiro, T.; Yamashiro, A.; Inoue, M.; Maki, M. Genetic diversity and divergence in populations of the threatened grassland perennial Vincetoxicum atratum (Apocynaceae-Asclepiadoideae) in Japan. J. Hered. 2016, 107, 455-462. [CrossRef] [PubMed]

27. Bhat, P.; Hegde, G.; Hegde, G.R. Ethnomedicinal practices in different communities of Uttara Kannada district of Karnataka for treatment of wounds. J. Ethnopharmacol. 2012, 143, 501-514. [CrossRef]

28. Singh, A.; Uppal, G.K. Review on Carissa carandas-phytochemistry, ethno-pharmacology, and micropropagation as conservation strategy. Asian J. Pharm. Clin. Res. 2015, 8, 26-30.

29. Bhadane, B.S.; Patil, M.P.; Maheshwari, V.L.; Patil, R.H. Ethnopharmacology, phytochemistry, and biotechnological advances of family Apocynaceae: A review. Phytother. Res. 2018, 32, 1181-1210. [CrossRef]

30. El-Gazzar, A.E.; Hamza, M. The subdivision of Asclepiadaceae. Phytologia 1980, 45, 1-16. [CrossRef]

31. Trivedi, B.; Upadhyay, N. Morphological studies in Apocynaceae: Epidermal structures. Geophytology 1977, 7, 29-37.

32. Amulya, L.; Hemanth Kumar, N.; Jagannath, S. Air pollution impact on micromorphological and biochemical response of Tabernaemontana divaricata L. (Gentianales: Apocynaceae) and Hamelia patens Jacq. (Gentianales: Rubiaceae). Braz. J. Biol. Sci. 2015, 2, 287-294.

33. Poornima, N.; Umarajan, K.; Babu, K. Studies on anatomical and phytochemical analysis of Oxystelma esculentum (Lf) R. br. Ex Schltes. Bot. Res. Int. 2009, 2, 239-243.

34. Kakkar, A.; Verma, D.; Suryavanshi, S.; Dubey, P. Characterization of chemical constituents of Calotropis procera. Chem. Nat. Compd. 2012, 48, 155-157. [CrossRef]

35. Souza, W. Técnicas Básicas de Microscopia Eletrônica Aplicadas às Ciências Biológicas; Sociedade Brasileira de Microscopia Eletrônica: Rio de Janeiro, Brazil, 1998.

36. Nassar, M.A.; El-Sahhar, K.F. Botanical Preparations and Microscopy (Microtechnique), In Arabic; Academic Bookshop: Giza, Egypt, 1998.

37. Farag, M.A.; Ammar, N.M.; El Gendy, A.N.; Mohsen, E. Effect of grilling as processing method on Zea mays (corn) metabolites composition as analyzed via SPME GC-MS and chemometrics. J. Food Process. Pres. 2019, 43, e14165. [CrossRef]

38. Farag, M.A.; Mohsen, E.; Abd El Nasser, G. Sensory metabolites profiling in Myristica fragrans (Nutmeg) organs and in response to roasting as analyzed via chemometric tools. LWT 2018, 97, 684-692. [CrossRef]

39. Legendre, P.; Legendre, L. Numerical Ecology, 3rd ed.; Elsevier: Amsterdam, The Netherlands, 2012.

40. Bashir, K.; Sohail, A.; Ali, U.; Ullah, A.; Ul Haq, Z.; Gul, B.; Ullah, I.; Asghar, M. Foliar micromorphology and its role in identification of the Apocynaceae taxa. Microsc. Res. Techniq. 2020, 83, 755-766. [CrossRef] [PubMed]

41. Barkatullah, M.I.; Jelani, G.; Ahmad, I. Leaf, stem bark and fruit anatomy of zanthoxylum armatum dc. (Rutaceae). Paki. J. Bot. 2014, 46, 1343-1349.

42. Salas, D.; Sinamban, E.; Buenavista, D. Comparative morpho-anatomical studies of Hoya incrassata and Hoya soligamiana (Apocynaceae) from Mount Hamiguitan, Philippines. Ruhuna J. Sci. 2018, 9, 1-9. [CrossRef] 
43. Nisa, S.U.; Shah, S.A.; Mumtaz, A.S.; Sultan, A. Stomatal novelties in Vincetoxicum arnottianum (Asclepiadeae: Asclepiadoideae: Apocynaceae). Flora 2019, 260, 151464. [CrossRef]

44. Akyalçın, H.; Özen, F.; Dülger, B. Anatomy, morphology, palynology and antimicrobial activity of Amsonia orientalis Decne. (Apocynaceae) growing in Turkey. Int. J. Bot. 2006, 2, 93-99.

45. Albert, S.; Padhiar, A.; Gandhi, D.; Nityanand, P. Morphological, anatomical and biochemical studies on the foliar galls of Alstonia scholaris (Apocynaceae). Braz. J. Bot. 2011, 34, 343-358. [CrossRef]

46. Formiga, A.T.; Isaias, R.M. Responses of the host plant tissues to gall induction in Aspidosperma spruceanum Müell. Arg. (Apocynaceae). Am. J. Plant Sci. 2011, 2, 823-834. [CrossRef]

47. El-Kashef, D.F.; Hamed, A.N.; Khalil, H.E.; Kamel, M.S. Botanical studies of the leaf of Pachypodium lamerei Drake, family Apocynaceae, cultivated in Egypt. J. Pharmacogn. Phytochem. 2015, 3, 40-45.

48. Thomas, V.; Dave, Y. Structure and development of follicles of Nerium indicum Mill.(Apocynaceae). Feddes Repert. 1991, 102, 399-407. [CrossRef]

49. Versiani, M.A.; Ahmed, S.K.; Ikram, A.; Ali, S.T.; Yasmeen, K.; Faizi, S. Chemical constituents and biological activities of Adenium obesum (Forsk.) Roem. et Schult. Chem. Biodivers. 2014, 11, 171-180. [CrossRef] [PubMed]

50. Vikas, G.; Payal, M. Phytochemical and pharmacological potential of Nerium oleander: A review. Int. J. Pharm. Sci. Res. 2010, 1, 21-27.

51. Warashina, T.; Noro, T. Steroidal glycosides from the roots of Asclepias curassavica. Chem. Pharm. Bull. 2008, 56, 315-322. [CrossRef]

52. Li, J.-Z.; Qing, C.; Chen, C.-X.; Hao, X.-J.; Liu, H.-Y. Cytotoxicity of cardenolides and cardenolide glycosides from Asclepias curassavica. Bioorg. Med. Chem. Lett. 2009, 19, 1956-1959. [CrossRef]

53. Haribal, M.; Renwick, J.A.A. Oviposition stimulants for the monarch butterfly: Flavonol glycosides from Asclepias curassavica. Phytochemistry 1996, 41, 139-144. [CrossRef]

54. Begum, S.; Adil, Q.; Siddiqui, B.S.; Siddiqui, S. Constituents of the leaves of Thevetia neriifolia. J. Nat. Prod. 1993, 56, 613-617. [CrossRef]

(C) 2020 by the authors. Licensee MDPI, Basel, Switzerland. This article is an open access article distributed under the terms and conditions of the Creative Commons Attribution (CC BY) license (http://creativecommons.org/licenses/by/4.0/). 